\title{
Modulation of the immune response in rheumatoid arthritis with strategically released rapamycin
}

\author{
PING SHAO, LINXIAO MA, YILE REN and HUIJIE LIU \\ Department of Rheumatology, The First People's Hospital of Lianyungang, Lianyungang, Jiangsu 222002, P.R. China
}

Received July 13, 2016; Accepted June 27, 2017

DOI: $10.3892 / \mathrm{mmr} .2017 .7285$

\begin{abstract}
Rheumatoid arthritis (RA) is a chronic inflammatory disease, which is associated with symptoms, including synovial membrane inflammatory pain, joint synovitis and stiffness. However, there are no effective methods available to cure this disease. In the present study, rapamycin was used to modulate immunity in RA. To limit the cytotoxicity of rapamycin, rapamycin was loaded into well-characterized biocompatible nanoparticles. In vitro, rapamycin particles downregulated the activation of dendritic cell surface markers, including $\mathrm{CD}^{+} 0^{+}$and $\mathrm{CD}^{4} 0^{+}$, upon interacting with macrophages. The rapamycin particles reduced the secretion of inflammatory cytokines, including interleukin (IL)-6, tumor necrosis factor (TNF) and IL-1 $\beta$, which are characteristic of RA. In vivo, the rapamycin particles decreased the symptoms of RA in mice, and the production of inflammatory cytokines was associated with the occurrence of RA. The present study partially revealed the interactions between rapamycin and two types of immune cell in RA disease, and may potentially offer a solution to improve the treatment of RA.
\end{abstract}

\section{Introduction}

Rheumatoid arthritis (RA) is a chronic inflammatory disease characterized by synovial membrane inflammation. The symptoms of RA include pain, stiffness and synovitis of the joints, resulting in articular destruction $(1,2)$. The causes of RA include genetic and environmental factors, which result in immune perturbation in the innate and adaptive immune system, with chronic inflammation being one of the most notable effects. In established RA synovitis, it has been demonstrated that the innate and adaptive immune systems are involved in tissue inflammation and destruction $(3,4)$. Studies have linked RA with a network of cytokines, and

Correspondence to: Dr Huijie Liu, Department of Rheumatology, The First Hospital of Lianyungang, 182 Tong Guan North Road, Lianyungang, Jiangsu 222002, P.R. China

E-mail: xiaoli2501@163.com

Key words: rheumatoid arthritis, rapamycin, dendritic cells, macrophage, particles, inflammation these multifunctional proteins can promote specific immune responses, including inflammation. For example, the cytokine tumor necrosis factor (TNF)- $\alpha$, can promote inflammation in RA, and has been used as a target for treating RA $(1,5)$. In addtion, studies have demonstrated that inflammatory cytokines, including IL-1 $\beta$ and IL-8, promote the progression of RA (6). Specifically, IL-1 $\beta$ is usually generated by the macrophages residing in the synovial lining, which contribute to joint inflammation and damage in RA (7). IL-8 usually arises from the fibroblast-like synoviocytes in RA, and can lead to joint damage and inflammation. Therefore, these cytokines are suitable indicators for RA disease and treatment (8). Although these results have been shown to be effective, further studies are required to elucidate the roles of major secondary immune tissues, including the spleen and lymph nodes, which are major organs involved in coordinating innate and adaptive immunity in this disease. Collagen-induced arthritis (CIA) has been widely used to investigate human RA disease due to their similarities (9). In mice, CIA can be initiated to examine the mechanism and treatment of RA. In this model, B- and T-lymphocytes are involved in the inflammatory responses by modulating the collagen type II responses, mimicking the innate and adaptive functions in RA (9-12).

Mammalian target of rapamycin (mTOR) is essential in regulating cellular metabolism through various signaling pathways (13). Rapamycin is an immunosuppressant, which has been approved by the Food and Drug Administration for regulating immune responses in organ transplantation (14). Rapamycin can regulate mTOR pathways by modulating cellular and antibody immunity (15). Due to its potent immunosuppressive effect, rapamycin has been reported to modulate RA by regulating the growth of synovial fibroblast cells, which are important in the development of RA (16). In another study, it was reported that rapamycin inhibits the inflammatory processes observed in adult rheumatoid arthritis, and this function indicates rapamycin is a promising immunosuppressant for patients requiring renal transplantation and suffering from RA $(17,18)$. However, although rapamycin is promising as an immunosuppressant, particularly for RA, the underlying mechanisms remain to be fully elucidated. Therefore, it is important to investigate these underlying mechanisms.

In the present study, the delivery of rapamycin within a biomaterial carrier for the treatment of RA was investigated. Rapamycin was loaded into the carrier at nanoscale and can be released in a controllable manner. Upon interacting in the 
in vitro and in vivo RA model, rapamycin had no effect on cell viability, however, the RA symptoms were reduced and the production of inflammatory cytokines was observed in the RA mice. These results provide novel insight of the potential use of rapamycin for treating $\mathrm{RA}$.

\section{Materials and methods}

Ethics statement. All experiments in the present study were performed according to the guidelines of the Animal Care and Use Committee of Lianyungang First Hospital (Jiangsu, China). The experiments were also performed according to the local and governmental laws on animal care and protection.

Materials. Bacterial lipopolysaccharide (LPS; Escherichia coli O55:B5) was obtained from Sigma-Aldrich; Merck Millipore (Darmstadt, Germany). RPMI 1640 cell culture medium and FBS were from VWR International (West Chester, PA, USA). Penicillin and streptomycin were from Thermo Fisher Scientific, Inc. (Waltham, MA, USA). The poly (lactide-co-glycolide) copolymer [PLGA; lactide:glycolide (50:50); MW=30,000-60,000] was from Sigma-Aldrich; Merck Millipore. Trypan blue was from VWR International.

Cells and animals. For cell culture, RMPI 1640 medium was supplemented with $10 \%$ FBS, $100 \mathrm{U}$ ml-1 penicillin and $100 \mathrm{mg} \mathrm{ml}-1$ and streptomycin. Cell culture was performed in $5 \% \mathrm{CO}_{2}$ at $37^{\circ} \mathrm{C}$. Male DBA/1J mice (age, 5-8 weeks old; weight, $\sim 20 \mathrm{~g}$ ) were obtained from the Animal Center at Lianyungang First Hospital. Mice were housed in a 12-h light/dark cycle at $21^{\circ} \mathrm{C}$ and $45 \%$ humidity, with free access to food and water.

Nanoparticle synthesis and characterization. Nanoparticles carrying rapamycin were generated using an emulsion method (19,20). Briefly, $10 \mathrm{mg}$ rapamycin and $50 \mathrm{mg}$ PLGA were dissolved in $2 \mathrm{ml}$ DCM, followed by sonication for 45 sec. The solution was then added in a drop-wise manner into PVA solution $(2 \% ; 2 \mathrm{ml})$. The mixture was then sonicated for $15 \mathrm{~min}$, and stirred with a magnetic bar at $600 \mathrm{x}$ g at $4^{\circ} \mathrm{C}$ for $2 \mathrm{~h}$. The particles were collected via centrifugation $(13,600 \mathrm{x} \mathrm{g}$ at $4^{\circ} \mathrm{C}$ for $7 \mathrm{~min}$ ), and were then washed twice with distilled water. The particles were lyophilized and stored at $-20^{\circ} \mathrm{C}$ prior to use. The morphology of the particles was assessed in images, captured using a scanning electron microscope (SEM; JEOL-JSM 7500F; JEOL, Ltd., Tokyo, Japan). The sizes of the particles were assessed using the Zetasizer Nano ZS instrument (Malvern Instruments, Inc., Westborough, MA, USA). For particle size measurement, the incident beam was scattered and detected at 90 degrees. An average of 12 runs (x3) were performed.

$R A$ induction and assessment. The RA mouse model was established following a previously reported method (21). Briefly, $10 \mathrm{mg}$ type II collagen was dissolved in $1 \mathrm{ml}$ acetic acid $(0.01 \mathrm{M})$. This solution $(100 \mu \mathrm{l})$ was injected intraperitoneally every 7 days for 56 days. RA was assessed macroscopically by using microcalipers to measure hind paw thickness. The lesions in the four paws were used to evaluate the severity of the arthritis. Each of the paws were graded between 0 and 3:
0, normal; 1, marginal swelling; 2, pronounced edematous swelling; 3 , joint rigidity. For the assessments, four groups of mice were included, as follows: The naïve group comprised mice without treatment, which was used as a negative control; the RA group comprised mice induced with RA, as another control to demonstrate treatment efficacy; the NP group comprised mice treated with empty particles $(1 \mathrm{mg})$ to examine the effect of the carrier on treatment; in the fourth group, to demonstrate the effect of rapamycin particles on treatment, $135 \mu \mathrm{g}$ rapamycin particles were used to treat the mice induced with RA to demonstrate the treatment efficacy.

Viability assays. Dendritic cells (DCs) were used to investigate the effect of rapamycin on cell viability. The cells were isolated from the spleen of naïve mice and were cultured in cell culture medium for $6 \mathrm{~h}$, followed by washing twice with PBS to remove any dead, free-floating cells. Trypan blue (1:1,000 in PBS) was used to stain the cells for viability assessment. The numbers of viable cells were counted using a cell counter (NanoEnTek-E1012V-EVE automated cell counter; NanoEnTek, Inc., Inc., Seoul, Korea).

ELISA assays. The ELISA assays were performed as follows: $100 \mu \mathrm{l}$ blood was collected from the abdominal artery of the mice. The blood samples were then centrifuged at $18,000 \mathrm{xg}$ at $4^{\circ} \mathrm{C}$ for $5 \mathrm{~min}$ to obtain the plasma, which was then stored at $-80^{\circ} \mathrm{C}$ prior to use. The levels of TNF, IL- 6 and IL- $1 \beta$ were assessed using ELISA kits according to the manufacturer's protocols. To determine the levels of cytokines in macrophages, the cells were treated with the following different sample group treatments for $48 \mathrm{~h}$ at $37^{\circ} \mathrm{C}$ : i) non-treated negative controls; ii) cells treated with LPS $(3 \mu \mathrm{g} / \mathrm{ml})$; iii) cells treated LPS $(3 \mu \mathrm{g} / \mathrm{ml})$ and nanoparticles $(250 \mu \mathrm{g} / \mathrm{ml})$; and iv) cells treated with LPS $(3 \mu \mathrm{g} / \mathrm{ml})$ and rapamycin-loaded nanoparticles $(50 \mu \mathrm{g}$ rapamycin per $\mathrm{ml}$, loaded in nanoparticles). For all ELISA assays, a standard curve was generated for quantification and $20 \mu \mathrm{l}$ supernatant was collected for use in these tests.

Macrophage and DC isolation. The CD11c-purified DCs were isolated from the spleens of mice. The cells were purified from the whole splenocytes using magnetic positive selection. The macrophages used in the present study were isolated from bone marrow according to the protocols described by the manufacturer of the kit and previous reports $(20,21)$. In the in vitro experiments, four treatment groups were included: No treatment, lipopolysaccharide (LPS) treatment, LPS+particle treatment and LPS+rapamycin particle treatment. LPS was used as a positive control for stimulating dendritic cells at a dose of $3 \mu \mathrm{g} / \mathrm{ml}$. In the in vitro experiments, the dose of rapamycin particles required to modulate DC activation was $60 \mu \mathrm{M}$.

Statistical analysis. Statistical analysis was performed using one-way analysis of variance with Turkey's post hoc test. GraphPad Prism software version 6.0 (GraphPad Software, Inc., La Jolla, CA, USA) was used for analysis. $\mathrm{P}<0.05$ was considered to indicate a statistically significant difference. All experiments were repeated three times with similar results. The experiments included three repeats for each assessment. In the animal experiments, each group contained five mice. 

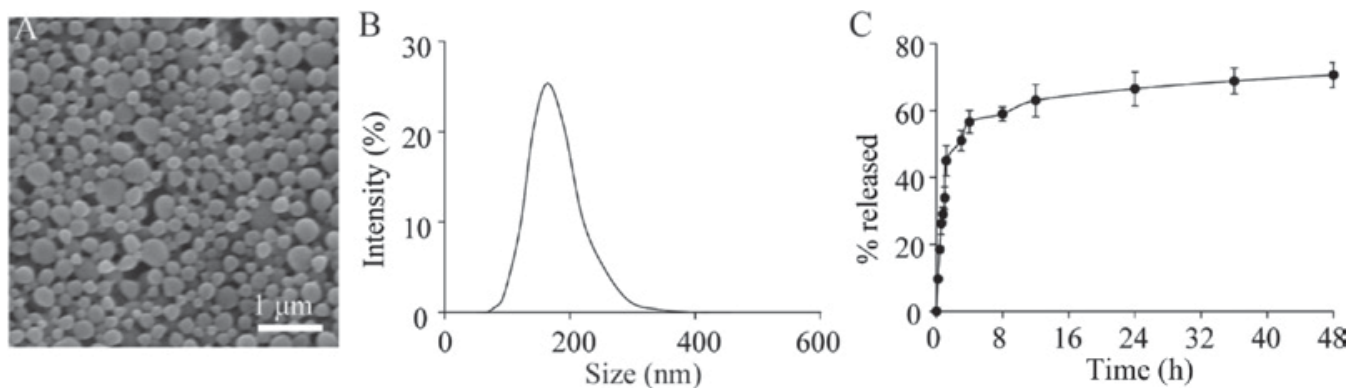

Figure 1. Characterization of rapamycin-loaded nanoparticles. (A) Scanning electron microscopy revealing the morphology of the rapamycin-loaded particles. (B) Size distribution of rapamycin particles. The particles had a diameter of $165 \pm 35 \mathrm{~nm}$. (C) Release profile of rapamycin from particles in PBS.

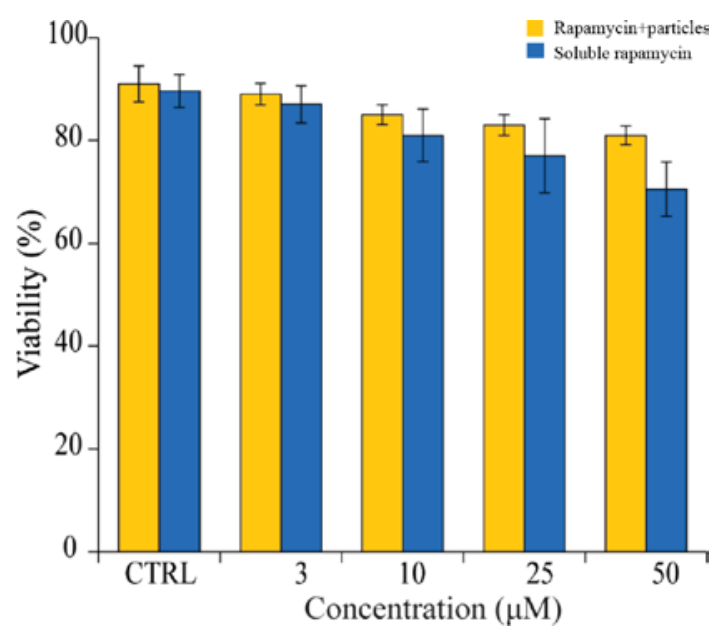

Figure 2. Effects of soluble rapamycin and rapamycin particles on splenocyte viability. Rapamycin had a marginal effect on cell viability. Rapamycin loaded in particles (orange bars) has less effect on cell viability, compared with soluble rapamycin (blue bars).

\section{Results}

Prior to experiments in the present study rapamycin was loaded into PLGA nanoparticles using an emulsion method. Under SEM, the particles had a spherical shape (Fig. 1A) Using dynamic light scattering; it was found that the rapamycin-loaded nanoparticles had a diameter of $\sim 165 \pm 35 \mathrm{~nm}$ (Fig. 1B). The rapamycin within the particles was released during incubation in PBS; $\sim 70 \%$ of the rapamycin was released in the first $24 \mathrm{~h}$ of incubation (Fig. 1C). The loading test showed that there was $\sim 138 \pm 15 \mu \mathrm{g}$ rapamycin per mg of nanoparticles.

Following characterization of the rapamycin-loaded particles, the effect of rapamycin on cell viability was determined. In this assessment, two samples were used: Rapamycin in a soluble form and rapamycin loaded into particles. The results showed that rapamycin caused a marginal reduction in cell viability in vitro in the two types of sample, compared with cells in the untreated control (Fig. 2). Compared with rapamycin in a soluble form, rapamycin loaded in the particles markedly increased cell viability, even when a high dose $(\geq 25 \mu \mathrm{M}$ ) was used. This indicated that a biomaterial carrier reduced the cytotoxicity of the rapamycin in vitro.

Following assessment of the in vitro cytotoxicity of rapamycin/NP, the interaction between rapamycin/NP and DCs, which are vital in innate and adaptive immunity, was assessed. As LPS is one the adjuvants, which has been successfully used to induce the RA mice model, the present study used LPS to examine the modulatory effects of rapamycin/NP. The results showed that LPS treatment significantly upregulated DC surface markers, $\mathrm{CD}^{+} 0^{+}$and $\mathrm{CD} 40^{+}$(Fig. 3A and B). Following treatment of the cells with rapamycin/NP, the activation of these surface markers $\left(\mathrm{CD}^{+} 0^{+}\right.$and $\left.\mathrm{CD} 40^{+}\right)$was downregulated (Fig. 3A and B). The empty PLGA particles did not activate these two surface markers (Fig. 3A and B) indicating that the modulatory effects were from the rapamycin present within the particles.

Following the assessment of the effect of rapamycin on DCs, the present study investigated the effect of rapamycin on the production of cytokines from macrophages. To quantitatively assess the response of macrophages to rapamycin particles, the production of inflammatory cytokines from macrophages stimulated with LPS was examined. Following LPS stimulation, there was an increased production of inflammatory cytokines IL-6, TNF and IL-1 $\beta$ (Fig. 4A-C). Treatment with the empty PLGA nanoparticles (NP+LPS in Fig. 4) did not decrease the production of these inflammatory cytokines (Fig. 4A-C). By contrast, following the addition of rapamycin into the particles (rapamycin/NP), the levels of IL-6, TNF and IL-1 $\beta$ were significantly reduced (Fig. 4A-C) indicating the regulatory functions of rapamycin in macrophage activation.

Following the in vitro assessments, the present study investigated the in vivo effects of rapamycin particles in a mice RA model. The clinical scores of mice were determined on exposure to different treatments: Naïve mice (control), untreated mice (induced with RA only), NP (RA mice treated with empty particles) and rapamycin/NP mice (RA mice treated with rapamycin loaded in particles). The results of the clinical score assessment showed that, following daily rapamycin/NP treatment, there was a significant reduction in clinical score in the RA mice. By contrast, the mice treated with empty NP and the untreated RA mice exhibited relatively higher clinical scoring of RA symptoms (Fig. 5A). Another parameter used to indicate the treatment efficacy indirectly was the weights of the mice (Fig. 5B). The results indicated that, whereas the mice with no therapeutic treatment and those treated with empty particles (NP) exhibited weight loss in the 50 days, the mice treated with rapamycin/NP maintained a relatively stable weight, indicating that rapamycin/NP assisted in maintaining a relatively healthy condition (Fig. 5B). In addition to clinical scores and mice weights, the present study assessed the production of inflammatory and regulatory cytokines in 

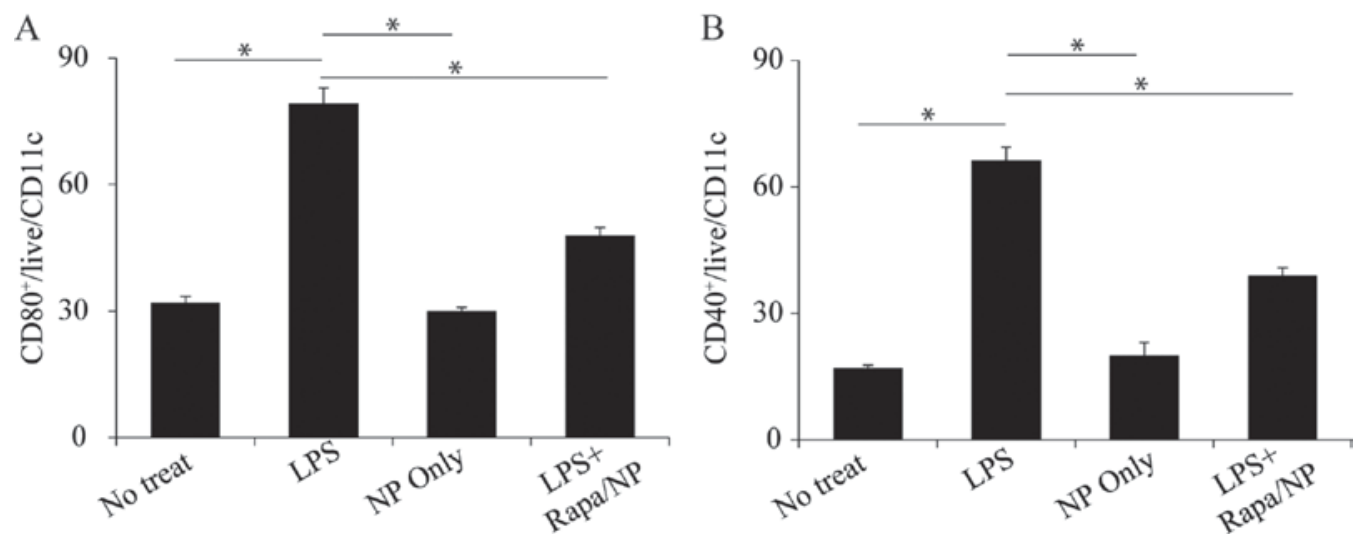

Figure 3. Rapamycin particles regulate dendritic cell activation. The activation of (A) CD80 and (B) CD40 markers by different samples was examined. Cells were treated with LPS, NP or LPS+rapamycin particles. Cells with no treatment were used as a control. "P<0.05. LPS, lipopolysaccharide; Rapa, rapamycin; NP, empty particles.
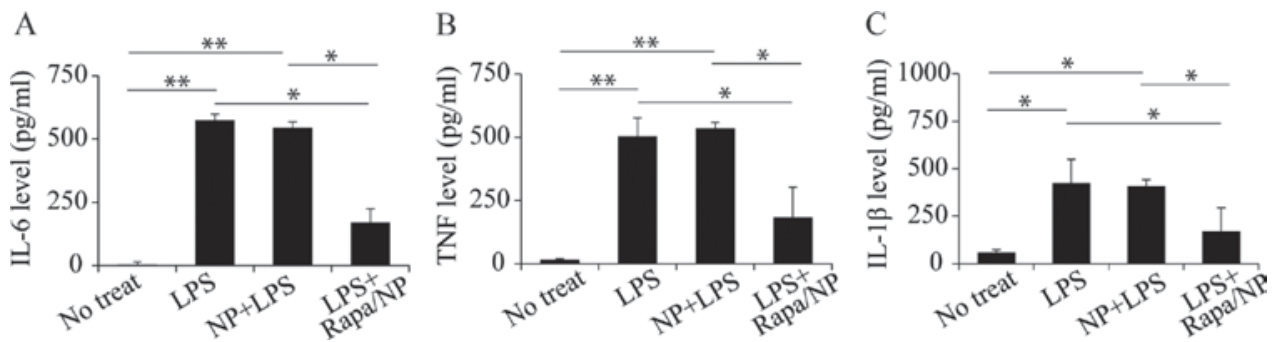

Figure 4. Production of cytokines from macrophages with different treatments. Secretion of (A) IL-6, (B) TNF and (C) IL1- $\beta$ from macrophages with different treatments. The cells were treated with LPS, LPS+NP or LPS+rapamycin particles. Cells with no treatment were used as a control. ${ }^{*} \mathrm{P}<0.05$ and ${ }^{* * *} \mathrm{P}<0.01$. IL, interleukin; TNF, tumor necrosis factor; LPS, lipopolysaccharide; Rapa, rapamycin; NP, empty particles.
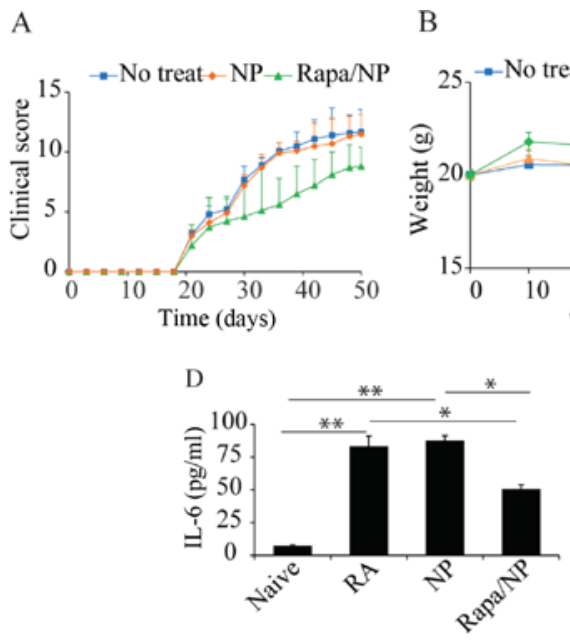

B

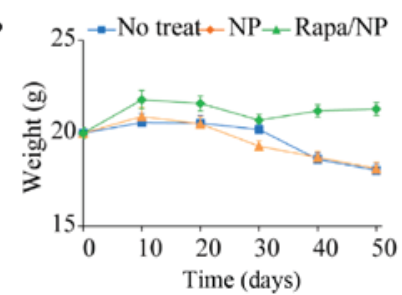

C

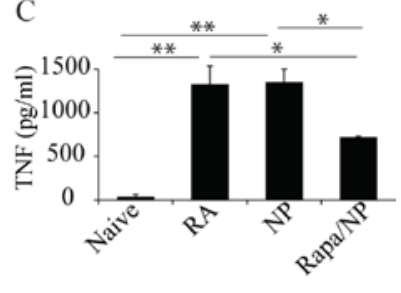

E

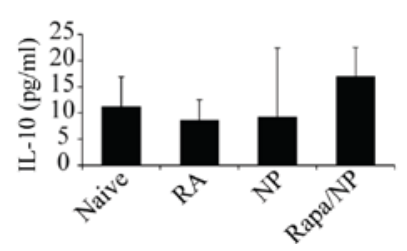

Figure 5. In vivo assessment of rapamycin particles in the RA model. (A) Clinical scores of Naïve mice, mice treated with empty NP and mice treated with rapamycin particles. Mice treated with rapamycin particles had lower clinical scores, compared with those in the other two groups. (B) Weights of mice. Naïve mice and mice treated with NP were used as controls, which exhibited reduced weight over time. (C) TNF, (D) IL-6 and (E) IL-10 were present in the sera of mice. ${ }^{*} \mathrm{P}<0.05$ and ${ }^{* *} \mathrm{P}<0.01$. RA, rheumatoid arthritis; Naïve, untreated; NP, empty particles; Rapa/NP mice with RA and rapamycin particle treatment; TNF, tumor necrosis factor; IL, interleukin.

mice receiving the different treatments. Compared with the naïve mice, there was a significant increase in the production of inflammatory cytokines IL-6 and TNF in the mice induced with RA (Fig. 5C and D). Treatment with empty NP did not induce any treatment efficacy in terms of the production of inflammatory cytokines (Fig. 5C and D). Following treatment with rapamycin particles, there was a marked reduction in the levels of these two inflammatory cytokines (Fig. 5C and D). For the production of regulatory cytokine, IL-10, there was a marginally lower level of IL-10 in the RA mice, compared with that in the naïve mice (Fig. 5E). In the RA mice treated with rapamycin, there was a marginal increase in the production 
of IL-10 (Fig. 5E), indicating that rapamycin/NP exerted a regulatory effect, to a degree, in RA treatment.

\section{Discussion}

As with the majority of autoimmune diseases, RA consists of two distinct components: Damage in self-tolerance and chronic inflammation in relevant organs. Specifically, RA is associated with chronic inflammation in the synovial tissues, in addition to erosion and destruction in bone and cartilage. To control the progression of this disease, multiple immune suppressants, including cyclosporin A, mizoribine and cyclophosphamide, have been used. Rapamycin, the FDA-approved immunosuppressant used in organ transplantation, has been reported to be effective in regulating RA in several clinical cases (16-18). However, due to limited investigations of this drug in RA, the underlying mechanism remains to be elucidated. Therefore, the present study investigated the in vitro and in vivo efficacy of rapamycin in regulating immunity in RA.

Studies have confirmed that DCs and macrophages are essential in autoimmune diseases, including RA (22-24). Specifically, DCs can contribute to the pathogenesis of RA via different mechanisms. First, DCs can prime major histocompatibility complex-restricted autoimmune responses in major immune organs, including lymph nodes, where the activation of DCs can promote the production of autoantibody and chronic inflammatory pathology, which are features of RA $(25,26)$. Secondly, DCs infiltrate into synovial tissue, and fluid can uptake and present antigens associated with the progression of RA, which contributes to the perpetuation of RA. In addition, in vivo histological experiments have shown that DCs can promote inflammation in ectopic lymphoid tissues $(27,28)$. Therefore, the present study investigated the effects of rapamycin on the activation of DC surface markers, which is required by DCs to perform their functions in innate and adaptive immunity. The results showed that rapamycin carried in particles downregulated the activation of DC surface markers in vitro (Fig. 3A and B), which indicated that regulation of DC activation by rapamycin particles may be a potential strategy for the regulation of RA. As antigen-presenting cells, DCs are important in mediating immunity and immune tolerance. Although the exact roles of DCs in RA remain to be fully elucidated, evidence suggests the roles of DCs are in disease progression and maintenance (14). This is consistent with the findings of the present study, in which rapamycin particles regulated RA disease by modulating DC activation. Similarly, the present study revealed that rapamycin particles regulated the secretion of inflammatory cytokines from macrophages (Fig. 4A-C). Macrophages were investigated as they are important in the pathophysiology of inflammation and atherosclerosis $(22,23,29,30)$. In RA, there is marked activation and infiltration of macrophages to inflammatory sites (31-33). It has been demonstrated that one major contribution of macrophages in RA is the enhanced production of TNF (34). In the present study, it was demonstrated that rapamycin particles regulated the production of TNF and other inflammatory cytokines (IL-6 and IL1- $\beta$ ), as shown in Fig. 4-C. These data, together with previous reports, partially explains the clinical observations that rapamycin regulates RA $(17,19)$.
Several immune therapies are being developed for the treatment of RA, including targeting $\mathrm{T}$ cell and B cell functions. In particular, the regulation of inflammatory cytokines, including TNF, IL- 6 and IL-1 $\beta$, is a focus of interest in investigations $(35,36)$. Therefore, the present study also assessed the in vivo modulatory effects of rapamycin particles in regulating RA. The clinical scores showed improved RA symptoms and stable weight maintenance in the mice treated with rapamycin particles (Fig. 5A and B). Considering the significance of inflammatory cytokines in regulating RA, the present study assessed the levels of TNF, IL- 6 and IL-1 $\beta$ in mice exposed to different treatments. There were reductions in the levels of TNF, IL- 6 and IL-1 $\beta$ in the mice treated with rapamycin particles, indicating reduced inflammation in vivo. In addition to the clinical scores, these data indicated that rapamycin particles modulated RA inflammation. However, the present study did not investigate the roles of regulatory immune cells, including regulatory $\mathrm{T}$ cells, in treatment. This, and the in vivo responses of DCs, macrophages and other immune cells, including natural killer cells, require determination in future investigations.

In conclusion, the present study investigated the use of rapamycin to modulate immunity in RA. It was found that carrying rapamycin within a biocompatible material reduced the toxicity of the drug. In vitro experiments indicated that rapamycin regulated the activation of DCs and macrophages. In vivo experiments demonstrated that rapamycin particles reduced RA clinical scores and reduced the production of inflammatory cytokines. These results assist in understanding the interactions between immune cells and rapamycin, and suggest a potential method for the treatment of RA.

\section{Acknowledgements}

This study was supported by the First Hospital of Lianyungang for Young Researchers (grant no. FHL0513259).

\section{References}

1. Dai Y and Hu S: Recent insights into the role of autophagy in the pathogenesis of rheumatoid arthritis. Rheumatology (Oxford) 55: 403-410, 2016.

2. Zvaifler NJ: Pathogenesis of the joint disease of rheumatoid-arthritis. Am J Med 75: 3-8, 1983.

3. Wang D, Li Y, Liu Y and Shi G: The role of autoreactive T cell in the pathogenesis of rheumatoid arthritis and implications for T cell targeted vaccine therapy. Minerva Med 106: 157-167, 2015.

4. Tsokos GC and Magilavy DB: Cellular immune-responses in the pathogenesis of juvenile rheumatoid-arthritis. Eos-Riv Immunol 7: 27-31, 1987.

5. Kay J and Calabrese L: The role of interleukin-1 in the pathogenesis of rheumatoid arthritis. Rheumatology (Oxford) 43 (Suppl 3): iii2-iii9, 2004.

6. Chu CQ, Field M, Allard S, Abney E, Feldmann M and Maini RN: Detection of cytokines at the cartilage/pannus junction in patients with rheumatoid arthritis: Implications for the role of cytokines in cartilage destruction and repair. Brit J Rheumatol 31: 653-661, 1992.

7. Deleuran BW, Chu CQ, Field M, Brennan FM, Katsikis P, Feldmann M and Maini RN: Localization of interleukin-1 alpha, type 1 interleukin-1 receptor and interleukin-1 receptor antagonist in the synovial membrane and cartilage/pannus junction in rheumatoid arthritis. Br J Rheumatol 31: 801-809, 1992.

8. Georganas C, Liu H, Perlman H, Hoffmann A, Thimmapaya B and Pope RM: Regulation of IL-6 and IL-8 expression in rheumatoid arthritis synovial fibroblasts: The dominant role for NF-kappa B but not C/EBP beta or c-Jun. J Immunol 165: 7199-7206, 2000. 
9. Brand DD, Latham KA and Rosloniec EF: Collagen-induced arthritis. Nat Protoc 2: 1269-1275, 2007.

10. Malfait AM, Williams RO, Malik AS, Maini RN and Feldmann M: Chronic relapsing homologous collagen-induced arthritis in DBA/1 mice as a model for testing disease-modifying and remission-inducing therapies. Arthritis Rheum 44: $1215-1224,2001$.

11. Inglis JJ, Notley CA, Essex D, Wilson AW, Feldmann M, Anand P and Williams R: Collagen-induced arthritis as a model of hyperalgesia: Functional and cellular analysis of the analgesic actions of tumor necrosis factor blockade. Arthritis Rheum 56 4015-4023, 2007.

12. Durie FH, Fava RA and Noelle RJ: Collagen-induced arthritis as a model of rheumatoid arthritis. Clin Immunol Immunop 73: 11-18, 1994.

13. Soliman GA: The role of mechanistic target of rapamycin (mTOR) complexes signaling in the immune responses. Nutrients 5: 2231-2257, 2013.

14. Macdonald AS: Use of mTOR inhibitors in human organ transplantation. Expert Rev Clin Immunol 3: 423-436, 2007.

15. Huo Y, Iadevaia V and Proud CG: Differing effects of rapamycin and mTOR kinase inhibitors on protein synthesis. Biochem Soc Trans 39: 446-450, 2011.

16. Foroncewicz B, Mucha K, Paczek L, Chmura A and Rowiński W: Efficacy of rapamycin in patient with juvenile rheumatoid arthritis. Transpl Int 18: 366-368, 2005.

17. Migita K, Eguchi K, aoyagi T, Tsukada T, Tsuboi M, Kawabe Y and Nagataki S: The effects of the immunosuppressant rapamycin on the growth of rheumatoid arthritis (RA) synovial fibroblast. Clin Exp Immunol 104: 86-91, 1996.

18. Lopez-Hoyos M, Rodrigo E, Fernandez-Fresnedo G, Martinez-Taboada VM, Valero R and Arias M: Lack of effect of rapamycin in anti-CCP antibody production in a rheumatoid arthritis kidney allograft recipient. Clin Exp Rheumatol 23 529-531, 2005

19. Fahmy TM, Samstein RM, Harness CC and Mark Saltzman W: Surface modification of biodegradable polyesters with fatty acid conjugates for improved drug targeting. Biomaterials 26 : $5727-5736,2005$

20. Park J, Fong PM, Lu J, Russell KS, Booth CJ, Saltzman WM and Fahmy TM: PEGylated PLGA nanoparticles for the improved delivery of doxorubicin. Nanomedicine 5: 410-418, 2009.

21. Bendele AM: Animal models of rheumatoid arthritis. J Musculoskel Neuron Interact 1: 377-385, 2001

22. Vuaillat-Savarin C, Wiermckx A, Rey C, Lachuer J, Belin MF and Nataf S: Microarray analysis of microglia versus bone marrow-derived macrophages. J Neuroimmunol 178: 134-135, 2006.

23. Mohammad MK, Morran M, Slotterbeck B, Leaman DW, Sun Y, Grafenstein Hv, Hong SC and McInerney MF: Dysregulated toll-like receptor expression and signaling in bone marrow-derived macrophages at the onset of diabetes in the non-obese diabetic mouse. Int Immunol 18: 1101-1113, 2006.
24. Cejka D, Hayer S, Niederreiter B, Sieghart W, Fuereder T, Zwerina $J$ and Schett G: Mammalian target of rapamycin signaling is crucial for joint destruction in experimental arthritis and is activated in osteoclasts from patients with rheumatoid arthritis. Arthritis Rheum 62: 2294-2302, 2010.

25. Leung BP, Conacher M, Hunter D, McInnes IB, Liew FY and Brewer JM: A novel dendritic cell-induced model of erosive inflammatory arthritis: Distinct roles for dendritic cells in T cell activation and induction of local inflammation. J Immunol 169: 7071-7077, 2002.

26. Dittel BN, Visintin I, Merchant RM and Janeway CA Jr: Presentation of the self antigen myelin basic protein by dendritic cells leads to experimental autoimmune encephalomyelitis. J Immunol 163: 32-39, 1999.

27. Page G, Lebecque S and Miossec P: Anatomic localization of immature and mature dendritic cells in an ectopic lymphoid organ: Correlation with selective chemokine expression in rheumatoid synovium. J Immunol 168: 5333-5341, 2002.

28. Ludewig B, Odermatt B, Landmann S, Hengartner H and Zinkernagel RM: Dendritic cells induce autoimmune diabetes and maintain disease via de novo formation of local lymphoid tissue. J Exp Med 188: 1493-1501, 1998.

29. Libby P, Ridker PM and Hansson GK: Progress and challenges in translating the biology of atherosclerosis. Nature 473: 317-325, 2011.

30. Gordon S and Taylor PR: Monocyte and macrophage heterogeneity. Nat Rev Immunol 5: 953-964, 2005.

31. Swirski FK, Nahrendorf M, Etzrodt M, Wildgruber $M$, Cortez-Retamozo V, Panizzi P, Figueiredo JL, Kohler RH, Chudnovskiy A, Waterman P, et al: Identification of splenic reservoir monocytes and their deployment to inflammatory sites. Science 325: 612-616, 2009.

32. Torsteinsdóttir I, Arvidson NG, Hällgren R and Håkansson L: Monocyte activation in rheumatoid arthritis (RA): Increased integrin, $\mathrm{Fc}$ gamma and complement receptor expression and the effect of glucocorticoids. Clin Exp Immunol 115: 554-560, 1999.

33. Lioté F, Boval-Boizard B, Weill D, Kuntz D and Wautier JL: Blood monocyte activation in rheumatoid arthritis: Increased monocyte adhesiveness, integrin expression, and cytokine release. Clin Exp Immunol 106: 13-19, 1996.

34. Kinne RW, Stuhlmüller B and Burmester GR: Cells of the synovium in rheumatoid arthritis. Macrophages. Arthritis Res Ther 9: 224, 2007.

35. Kremer JM, Westhovens R, Leon M, Di Giorgio E, Alten R, Steinfeld S, Russell A, Dougados M, Emery P, Nuamah IF, et al: Treatment of rheumatoid arthritis by selective inhibition of T-cell activation with fusion protein CTLA4Ig. N Engl J Med 349: 1907-1915, 2003

36. Buch MH, Smolen JS, Betteridge N, Breedveld FC, Burmester G, Dörner T, Ferraccioli G, Gottenberg JE, Isaacs J, Kvien TK, et al: Updated consensus statement on the use of rituximab in patients with rheumatoid arthritis. Ann Rheum Dis 70: 909-920, 2011. 